С. С. Имихелова, Б. Г. Хубусгеева. Дневниковая книга Б. Дугарова «Сутра мгновений» как проза поэта

Научная статья

УДК 821.512 .31

DOI 10.18101/2686-7095-2021-2-45-52

\title{
ДНЕВНИКОВАЯ КНИГА Б. ДУГАРОВА «СУТРА МГНОВЕНИЙ» КАК ПРОЗА ПОЭТА
}

\section{(С) Имихелова Светлана Степановна}

доктор филологических наук, профессор

кафедры русской и зарубежной литературы,

Бурятский государственный университет имени Доржи Баназарова

Россия, 670000, г. Улан-Удэ, ул. Ранжурова, 6

223015@mail.ru

\section{(C) Хубусгеева Баярма Гуржабовна}

учитель русского языка и литературы, районный центр дополнительного образования «Курумканский район»

Россия, Республика Бурятия, Курумканский район,

с. Курумкан, ул. Балдакова, 45А

bkhubusgeeva@mail.ru

В статье дается представление о поэтическом характере дневниковой прозы бурятского поэта Баира Дугарова в книге «Сутра мгновений» (2011). Подчеркивается мысль о своеобразном соединении, переплетении прозы и поэзии, когда поэтические высказывания дополняют, осмысляют прозаическую часть книги, что позволяет определить ее жанровую природу. Утверждается, что для бурятского русскоязычного поэта, живущего на перекрестке культур, вполне закономерно продолжение такого явления русской литературы, как проза поэта. В то же время существование на границе двух инстанций - прозы и поэзии - позволяет автору-поэту выразить и национальный облик своего творчества. Отмечается, что центральная идея книги связана с наболевшей личной драмой героя-автора, в своем самопознании, самоопределении восстанавливающего историческую память в сознании современников. Делается вывод о том, что феномен прозы поэта во многом вызван манифестацией исторических и эстетических взглядов автора книги.

Ключевые слова: дневник, герой-автор, проза поэта, стихотворение в прозе, самоопределение, природа поэтического творчества

\section{Для цитирования}

Имихелова С. С., Хубусгеева Б. Г. Дневниковая книга Б. Дугарова «Сутра мгновений» как проза поэта // Вестник Бурятского государственного университета. Филология. 2021. Вып. 2. С. 45-52.

В 2011 г. народный поэт Бурятии Баир Дугаров опубликовал книгу «Сутра мгновений», в основу которой вошли не предназначенные для публикации дневниковые записи одного года - 1982-го. Эти записи представились автору интересными с позиции другого времени, с высоты жизненного и творческого опыта. Документально-автобиографические наброски из дневника тридцатилетней давности перемежаются «стихотворными пассажами», «стихами на листках календаря» для объяснения самим автором необычного жанра этой книги: «...о жанровых особенностях моих записок в целом я не берусь судить. Могу лишь сказать 
постфактум, что такая прозопоэтическая манера была в ходу у хронистов степного Востока» [2, с. 6]. Тем самым автор оглядывается на восточную традицию, закрепленную не только в средневековом памятнике 1240 г. «Сокровенное сказание монголов», но и в жизнеописании «Намтар» монгольского монахаотшельника и поэта Миларайбы (1040-1123), над переводом которого трудился сотрудник научного института Дугаров в 1982 г. (и сейчас он, доктор филологических наук, по-прежнему работает в этом же институте).

Не забывает автор книги «Сутра мгновений» (далее - «СМ») традицию русской поэзии в этом экспериментальном жанре, недаром, будучи билингвом, для выражения индивидуальной поэтической мысли и своего творческого «я» он выбрал русский язык. Традиция прозы поэта берет начало в Серебряном веке, как утверждает в своей книге «Стих и проза в русской литературе» Р. Якобсон: «Русская литература XIX в. не знает прозы поэта в современном понимании этого слова: стих и проза, поэт и прозаик «разведены» по различным полюсам литературы, а поэзия и проза, безусловно, испытывая постоянное взаимное влияние, тем не менее сохраняют свою структурную монолитность. Перелом намечается на рубеже веков, когда благодаря появлению русского символизма инициатива вновь начинает переходить в руки поэзии. Именно в это время появляется новая “серия” русских верлибров, активизируется интерес к другим формам, так или иначе синтезирующим стих и прозу в классическом понимании этих понятий; тогда же появляются и первые образцы того, что мы называем прозой поэта» [5, c. 36].

Автор «СМ» обходится близким и интимным материалом - материалом собственной жизни, дневниковая форма которого вбирает в себя поэтические комментарии-умозаключения, превращающие субъективно-авторские мысли и чувства в художественное обобщение. Вот почему документальный стиль дневниковых заметок неизбежно переводится в повествование эссеистического характера. И тогда вполне бытовой эпизод дополняется фрагментом, который вносит сильную лирическую струю, настроенную на восточный лад. После заметки о чтении стихотворений Р. Тагора, одно из которых называлось «Второе рождение», следует размышление:

«Кто не лазил по деревьям в детстве и не ходил босиком в детстве - ущербен, хотя никогда этого, может быть, не поймет. Первое рождение - от лона природы матери, второе рождение - в создании собственного духовного мира. Не отсюда ли понятие “дваждырожденные”?

Человек должен открывать мир внутри себя, а не искать себя по свету. Есть в монгольских языках выражение “хунтурэлтэн” — “рожденный человеком”. По буддийским представлениям, из всех форм перерождений - божественных и земных — именно человек считается кармическим стержнем Вселенной. Но только осознаем ли мы это? <...

Поэтам не возбраняется думать о нирване. А все-таки, что значит нирвана? Путь к себе, или путь над собой. Высокие птицы летят в поднебесье, не оставляя тени на земле» [2, c. 109].

Мысль о стремлении человека к высокому, духовному таит под собой великолепный подтекст, свойственный поэзии, заставляет читателя вместе с автором задуматься о ее особом предназначении. Поиски собственного духовного мира, или тяга к самоопределению, - одна из главных тем в книге «СМ», где геройавтор постоянно сопрягает ее со своими историческими и поэтическими занятиями. Соединение времени создания дневника 1982 г. и времени его опубликова- 
С. С. Имихелова, Б. Г. Хубусгеева. Дневниковая книга Б. Дугарова «Сутра мгновений» как проза поэта

ния отразилось в облике героя-автора как человека, сохраняющего в памяти историческое прошлое Центральной Азии, быт и занятия кочевников. И бытовая зарисовка из современных реалий часто напоминает о далекой истории. Так, записывая, как во время пребывания в Улан-Баторе его угощали монгольским чаем, он не может совладать со слуховой ассоциацией, подсказывающей звуки хура, музыкального инструмента монголов: «Зутран-чай - напиток номадов, изобретенный, наверное, самим Чингисханом, если не раньше, силу вселял и уверенность в дальнем пути. Хур одинокий звучал в руках седовласой старухи и путников провожал старинной тягучей мелодией, от которой сжималось сердце в груди...» [2, с. 414].

Время для автора в книге «СМ» постоянно отзывается этой оппозицией: прошлое / настоящее, мимолетность / вечность, которая перестает быть таковой, потому что в его сознании причудливо совмещаются несовместимые части, чтобы обозначить бесконечность жизни: «Кто вспомнит нас через сто или тысячу лет, о нас, о смертных, сидящих на гобийском пикнике и беззаботно пирующих на фоне пустыни? Мысли о бренности обостряют ощущение жизни» [2, с. 286]. Подобные мысли рождаются у автора дневника во время реальной поездки в Монголию и на глазах читателя превращаются в поэтическое высказывание.

Обе части книги «СМ» - прозаическая и поэтическая - объединены общим нервом - внутренней драмой автора, ощущаемой героем-автором как отпечаток некоего разлада в его мироощущении. О присутствии этой драмы в поэзии Дугарова не раз писали исследователи, анализирующие его лирику [1]. В книге «СМ» так же, как в лирике поэта, этот внутренний разлад сказывается в чувстве одиночества и тоски, обозначая мучительный поиск собственного пути в творчестве [3, c. 25]. Это чувство пронизывает многие страницы и там, где автор-поэт обращается к прошлому своего народа, к национальным истокам. Находясь в настоящем, он задумывается и с болью размышляет о том, что современные бурятмонголы забыли о своем великом прошлом и урбанизация усилила в них беспамятство иванов, не помнящих родства. Если в прозаическом повествовании это чувство звучит глухо, то в стихотворных фрагментах оно напрямую отзывается болью в душе и лирический герой даже называет ее источник. Специально для книги написан цикл стихотворений «Монолог бурмона», в котором герой считает себя последним бурят-монголом, когда восклицает:

И зачем меня Бог на тоску обрекает,

и заглушит ли боль степняка городское вино.

И тайком меня та же слеза обжигает,

что скатилась по лику распятого временем Жамцарано...

Мне осталось молчать и сродниться с проклятой тоскою,

улыбаться и петь с искаженным от боли лицом,

и стрела, что летит сквозь века над землею,

успокоится, видимо, в сердце моем [2, с. 333].

Выпущенная стрела из далекого прошлого находит покой, к сожалению, только в одном человеке - герое, чья боль, чьи слезы и тоска выражены с такой силой отчаяния, что он в своем драматичном состоянии увидит повторение трагедии, случившейся когда-то с «распятым временем» ученым-этнографом Цыбеном Жамцарано (как и многие известные деятели бурятского народа, в 1937 г. ученый был репрессирован и умер лагере). На протяжении всей книги герой- 
автор передает - по разным поводам - свое сожаление, что его соотечественники не помнят законы и традиции своих предков, что историческое сознание, историческая память забыты, превращая человека в манкурта - образ из романа Ч. Айтматова. Эта идея звучит и в лирике, открывая метафорический смысл: герой страстно желает стать соединительным звеном между прошлым и настоящим, между двумя мирами - кочевым, степным и городским, цивилизационным. Этой идее посвящено лирическое стихотворение «Пеший всадник», вошедший в новую книгу стихов Дугарова «Последний кочевник» (2021).

Поэтическая ткань книги - это не только стихотворения, комментирующие прозаическую канву книги. Это еще так называемая прозопоэзия, или стихотворения в прозе, когда создается особая поэтическая образность, воздействующая на эмоциональное восприятие читателя. В цикл «Монолог бурмона» включено также следующее стихотворение в прозе:

«Когда солнце клубится на закате красным заревом и облака проплывают в отсветах красно-багрового цвета, мне всегда кажется, что это возвращаются из бездны столетий, оживая над хребтами, над волнистой чертой горизонта, тучи, самые грозные и самые печальные в мире тучи - тучи пыли, поднятые копытами монгольских туменов, навсегда растворившихся в пространстве, в народах, покоренных и не покоренных, только пыль возвращается снова на родину, только пыль. Пыл проходит набегов, а пыль остается. И она возвращается, пыль - застилая солнце. Это называется закатом» [2, с. 330].

Особый ритм, а также паузы, возникающие в лирическом высказывании, создают движение звука, напоминающего ритм барабана. Ритм усилен повторами слов «тучи», «пыль», аллитерацией «пыл - пыль», без которых картина заката выглядела бы безмятежной. Грозные тучи пыли застилают солнце, и видение красно-багрового заката передает тревогу в сознании героя, убежденного, что звуки чингисхановской конницы, скачущей «из бездны столетий» и поднимающей тучи пыли, отражаются в настоящем - в час заката. Понятно, что воображаемая картина заставляет читателя настроиться на одну волну с героем, в поэтичном и эмоциональном облике которого отражено обостренное чувство исторической личности.

Как в прозаической части герой-автор, находящийся в настоящем, совмещает и сохраняет в своей памяти историческое и культурное прошлое Центральной Азии, так и лирический герой в поэтических фрагментах желает возвратиться к своим истокам, стать соединительным звеном между миром Великой степи и современным миром. В герое поэтических пассажей видится мечтатель, чей вольный степной дух ощущается и в городском пространстве. Таков герой его лирики. Таков и герой-автор книги «СМ». И это проза поэта, потому что, по словам В. М. Марковича, ее характерными чертами являются фрагментарность изложения, приближенность соответствующих фрагментов к формам поэтической речи и близость устойчивых мотивов из лирики поэтов их прозаическим произведениям [4, с. 160-163].

Автор книги - современный кочевник, помнящий свою историю, трепетно относящийся к родной земле, почитающий народную мудрость. Так, запись о совете известного ученого фольклориста сделать переводы бурятских пословиц и поговорок наталкивает автора вспомнить пословицы, встречающиеся в эпосе «Гэсэр». И возникает поэтическое размышление: 
С. С. Имихелова, Б. Г. Хубусгеева. Дневниковая книга Б. Дугарова «Сутра мгновений» как проза поэта

«Бурятские изречения - народные краткостишия <..> отточены, словно камушкисамоцветы, и органичны, как дыхание, в родной языковой стихии. В них отражаются и образ вселенной кочевника, и мудрость, накопленная веками, проглядывает и чисто бурятский юмор. Есть пословица, в которой сформулировано кочевническое понятие о достойном мужчине: «Эрэ хүнэй досоо эмээлтэ морин багтаха» - Коль широк ты душою, то верится: конь с седлом в твоем сердце поместится» [2, с. 390].

Еще один образ в книге соединяет черты современного человека и потомка Великой степи. В стихотворении «Легенда о заблудшем волке», помещенном в период московской командировки, лирический герой, как затравленный волк из русской поэзии, носится по Москве, в чужом пространстве ощущая себя замученным и заблудшим. Сравнение себя с загнанным волком далее изменяется, и лирический герой после признания: «Электрички, вокзалы, метро прищемляли мой хвост» - становится небесным волком: «...оттого что я был / синим небом ниспосланный пес» [2, с. 152]. Основной лейтмотив лирики Дугарова о героекочевнике, ищущем свой путь в современном урбанистическом мире и поклоняющемся Вечному Синему небу, соответствует тому, каким видит себя геройавтор в дневниковой книге «СМ».

В записях событий 1982 г. присутствует уже упоминавшаяся поездка в УланБатор на Конгресс монголоведов. Один из дней пребывания в столице Монголии начинается с поэтичного описания утреннего пробуждения.

«Я проснулся от запаха трав, от резкого и нежного запаха трав. Он наполнил всю комнату, отдавая прохладой неведомых гор и дыханием ускакавшего ливня.

Я проснулся от запаха трав и степи. Я во многих бывал городах, просыпался от звона будильника, звавшего в будни, от пронзительных сигналов клаксонов, от скрежета тормозов машин у светофора.

Что за удивительный город, в котором впервые проснулся от запаха трав и ночного дождя. Или, может, все это приснилось мне наяву? Нет, все это было так, как есть, сквозь раскрытую дверь на балконе струился запах трав и рассветной прохлады, за мостом поднимались хребты Богдо-Улы. Сама Великая степь обступала со всех сторон оживающие при свете утреннего солнца улицы и кварталы» [2, с. 268].

В этом прозопоэтическом фрагменте степная трава выступает символом национальной и культурной принадлежности, ведь в поэтической традиции монголов она непосредственно сопряжена с образом степи, с личностью кочевника. Становясь стихотворением в прозе, повествование воспроизводит сознание героя-горожанина, для которого пространство степи выступает гораздо шире, чем просто фон его жизни, - это пространство движения его души.

В содержании и форме стихотворений в прозе, составившем поэтическую часть книги «СМ», объектом становится тонко чувствующая творческая личность самого поэта. А его самоанализ позволяет выявить не только психологический настрой, но и эстетический взгляд автобиографического героя-художника, осмысляющего смысл и назначение своего творчества. Вот запись о субботних занятиях московского командировочного в Ленинке (так называли в просторечии Российскую государственную библиотеку). Они связаны не только с научной востоковедной тематикой, но и с поэтическими интересами, такими как, например, чтение стихотворений любимого Рильке, «одного из самых странствующих поэтов XX века». Следует запись: «Одиночество Рильке - от исступленной приверженности к творчеству, поэтическому призванию». Записываются мысли по- 
эта, созвучные герою-автору, обожающему путешествовать. Он даже дает определение одному из романов Рильке: это «проза поэта», комментируя:

«По мысли автора, лицо поэта определяют не чувства, а опыт. Чтобы написать одну стоящую строку, нужно самому “перевидеть массу городов, людей и вещей”, испытать и хранить в сердце впечатления детства, образы любимых женщин и почувствовать дыхание смерти у изголовья умирающих. И все это должно быть переплавлено в твою собственную человеческую плоть, чтобы однажды при звездном часе перелилось в стихотворение» [2, с. 151].

Подобные прозаические пассажи сопровождаются поэтическим итогом в виде стихотворения в прозе. «Чем же я отличаюсь от людей, братьев моих - песчинок? Может, тем, что никогда не спешу за толпой, словно в запасе у меня целая вечность... Может, тем, что пишу стихи, говорят, неплохие, и тешу себя надеждой, что кто-то сверху все-таки смотрит за мной... » [СМ, с. 149]. В таких прозопоэтических фрагментах, которые рассыпаны по всей книге, объектом и субъектом становится лирический герой со своим поэтическим мировоззрением. «Люди в больших городах - данники суеты, всегда в спешке. Предпочитают метро и такси, нежели ходьбу. И хорошо, что есть на свете высокие деревья, под сенью которых порою бродят поэты, чтобы разделить свое одиночество с опадающими листьями. От прикосновения к осени чаще всего рождаются стихи» [2, с. 319].

В герое подобных поэтических пассажей видится мечтатель, чей вольный степной дух заточен в узком городском пространстве, но как поэт он способен преодолеть этот «плен». Это видно во фрагментах-записях о посещении родины предков - горной Оки. Описание многочисленных встреч в селе Хужир, родине отца, сопровождается поэтическими вставками, иные из них навеяны видами Саянских гор в форме свободного стиха, но с анафорической рифмой:

«И в такой тишине даже слышно, как лиственница качает ветвями,

эхо горного водопада, летевшего в брызгах в тисках крутых берегов.

И в такой тишине даже слышно, как белыми говорят стихами

облака с облаками и снега со снегами на вершинах поднебесных гольцов.

И в такой тишине жизнь человеческая кажется чудно мгновенной,

словно листик, слетевший с ветвей и растаявший в водовороте веков.

Только знают ли об этом горы - божественные пирамиды Вселенной,

только знает ли об этом песчинка, которая старше людей и богов» [2, с. 409].

Образ человека как листика или песчинки на фоне величественных гор решен в традиционно буддийском аспекте. В этой ситуации лист как художественный образ олицетворяет человека, а оппозиция человеческая жизнь / жизнь вечной природы воплощает мотив бренности человеческого существования. Но ведь человек, утверждает поэт, как образ маленькой песчинки тоже есть олицетворение мира природы, а значит, согласно философско-поэтическому мышлению, становится вечным в сравнении не только с человечеством, но и с богами.

Размышление на эту тему в другом месте книги, где герой-автор во время поездки в пустыню Гоби не перестает писать стихи, также превращается в стихотворение в прозе, которое предваряется рифмованными двустишиями:

«<...

В мире пустыни нет ни добра, ни зла.

Есть только тень травинки и тень орла». 
С. С. Имихелова, Б. Г. Хубусгеева. Дневниковая книга Б. Дугарова «Сутра мгновений» как проза поэта

Но даже в песках жизнь обозначена едва заметными штрихами. Приглядишься и видишь, как варан чертит свои мелкие зигзаги на осыпающемся подоле бархана. Смысл варана - скользить по песку, не оставляя ни следа, ни тени, до предела сливаясь с пустыней. Быть живою песчинкой пространства, которое кажется мертвым. Быть песчинкой среди тьмы песчинок, из которых слагаются барханы, как поэмы пространства слагаются из строчек троп, многоточий созвездий и четок столетий» [2, с. 286].

Поэтическая мысль движется от созерцания вроде бы мертвой пустыни, где только тени явлений и нет движения жизни, к пониманию того, что каждая «живая песчинка» сложила тьмы песчинок в барханы, а барханы сложились в поэмы. Так же в поэзии: строчки, многоточия слагают «четки столетий». В этом видится поэтическая метафора буддийского просветления. Достижение просветления оказывается и целью поэзии. В этой буддийской идее отражена мысль автора книги о назначении художника - посредника между Небом и Землей: «Чем же я отличаюсь от людей, братьев моих - песчинок? Может, тем, что никогда не спешу за толпой, словно в запасе у меня целая вечность... Может, тем, что пишу стихи, говорят, неплохие, и тешу себя надеждой, что кто-то сверху все-таки смотрит за мной... » [2, с. 149].

Таким образом, экспериментальный жанр книги «СМ» соединяет бытовые зарисовки и философские размышления, прозаическое дневниковое описание и стихотворные пассажи, повествующего героя и лирического субъекта благодаря облику автора. Это главная его ипостась - личность, обладающая поэтическим даром. Вот почему многие страницы книги посвящены природе этого дара, поэтического призвания, которым в совершенной форме обладает автор. Так дневниковая форма, органично соединяясь со стихотворными фрагментами, превращается в прозу поэта. Происходит это благодаря тому, что ключевые события жизни, сокровенные мысли, драматичные состояния, размышления о природе творчества автора книги претворены в оригинальном жанровом облике.

Литература

1. Бальбуров Э. Испытание на прочность // Литературное обозрение. 1981. № 5. С. 75-76. Текст: непосредственный.

2. Дугаров Б. Сутра мгновений. Улан-Удэ: Республиканская типография, 2011. 440 с. Текст: непосредственный.

3. Имихелова С. С. Баир Дугаров. Литературная биография. Улан-Удэ: Изд-во Бурят. гос. ун-та, 2017. 72 с. Текст: непосредственный.

4. Маркович В. М. Автор и герой в романах Лермонтова и Пастернака («Герой нашего времени» - «Доктор Живаго») // Автор и текст: сборник статей. Санкт-Петербург, 1999. С. 150-179. Текст: непосредственный.

5. Якобсон Р. Работы по поэтике. Москва: Прогресс, 1987. 464 с. Текст: непосредственный.

Статья поступила в редакцию 25.05.2021; одобрена после рецензирования 30.05.2021; принята к публикации 30.06.2021. 


\title{
B. DUGAROV'S DIARY BOOK «SUTRA OF MOMENTS» AS THE PROSE OF A POET
}

\author{
Svetlana S. Imikhelova \\ Dr. Sci. (Phil.), Prof., \\ Dorzhi Banzarov's Buryat State University \\ 6 Ranzhurova St., Ulan-Ude, 670000, Russia \\ 223015@mail.ru \\ Bayarma G. Khubusgeeva \\ Research Assistant, \\ Dorzhi Banzarov's Buryat State University \\ 6 Ranzhurova St., Ulan-Ude, 670000, Russia \\ bkhubusgeeva@mail.ru
}

Abstract. The article reviews the poetic nature of the diary prose by the Buryat poet Bair Dugarov in the book "Sutra of Moments" (2011). It shows the idea of a connection and interweaving of prose and poetry, when poetic statements complement and comprehend the prose part of the book, which makes it possible to determine its genre nature. It is argued that for a Buryat Russian-speaking poet living at the crossroads of cultures, it is quite natural to continue such a phenomenon of Russian literature as the poet's prose. At the same time, the existence on the border of two instances - prose and poetry, allows the poet to express the national appearance of his work. It is noted that the central idea of the book is connected with the author's attempt to tell the reader his personal drama, i.e. with the problem of selfknowledge and self-determination. It is concluded that the attempt to reveal the phenomenon of the poet's prose in the book by B. Dugarov leads to an explanation of the aesthetic views of its author.

Keywords: diary, poet's prose, poem in prose, self-determination, nature of poetry

\section{For citation}

Imikhelova S. S., Khubusgeeva B. G. B. Dugarov's diary book «Sutra of Moments» as the prose of a poet. Bulletin of Buryat State University. Philology. 2021; 1: 45-52 (In Russ.).

The article was submitted 25.05.2021; approved after reviewing 30.05.2021; accepted for publication 30.06.2021. 